Pesq. Vet. Bras. 37(10):1074-1078, outubro 2017

DOI: $10.1590 / \mathrm{S} 0100-736 \mathrm{X} 2017001000006$

\title{
Situação epidemiológica da anemia infecciosa equina em equídeos de tração do Distrito Federal ${ }^{1}$
}

\author{
Daniella D.A. Moraes² ${ }^{2}$ Vitor S.P. Gonçalves ${ }^{4}$, Ana Lourdes A. de A. Mota ${ }^{4}$ \\ e José Renato J. Borges ${ }^{3 *}$
}

\begin{abstract}
Moraes D.D.A., Gonçalves V.S.P., Mota A.L.A.A. \& Borges J.R.J. 2017. [Epidemiological Status of Equine Infeccious Anemia in Working Equidae from the Federal District, Brazil.] Situação epidemiológica da anemia infecciosa equina em equídeos de tração do Distrito Federal. Pesquisa Veterinária Brasileira 37(10):1074-1078. Faculdade de Agronomia e Medicina Veterinária, Universidade de Brasília, Galpão 3, Granja do Torto, Brasília, DF 70636-200, Brazil.E-mail: jrborges@unb.br

Equine Infectious Anaemia (EIA) is a disease that has worldwide distribution and it is caused by a lentivirus. The disease constrains the development of horse breeding in Brazil, leading to compulsory slaughter of test positive animals. The objective of this study was to estimate the prevalence of EIA in traction equids and identify potential risk factors in the Federal District. Three hundred and fifty (350) owners were randomly selected (Primary Sampling Units-PSU) and all equids (Secondary Sampling Units - SSU) from each owner were sampled, in a total of 496 animals. Blood samples were tested in LANAGRO/ MG using the agar-gel immunodiffusion test (AGID). An epidemiological questionnaire was used to collect data on potential risk factors associated with the disease. The prevalence of PSU (owners) was estimated at 2.29\% (95\% CI: 1.01-4.2\%) and the prevalence in animals was $1.81 \%$ (95\% CI: 0.55-3.07\%). Prevalence was higher in mules than in horses. None of the other variables analyzed as potential risk factors was associated to the presence of the disease. The present study demonstrated that the prevalence of EIA in traction equids is low in the Federal District, which strengthens the case for the maintaining the test-and-cull policy and the need for disease surveillance measures aimed at eradicating the disease.
\end{abstract}

INDEX TERMS: Equine infectious anaemia, EIA, traction equidae, prevalence, Brasília, DF.

RESUMO.- A anemia infecciosa equina (AIE) é uma doença causada por um lentivirus que possui distribuição mundial. Essa enfermidade é um entrave ao desenvolvimento da equinocultura no Brasil devido à obrigatoriedade de eutanásia dos animais positivos. Este trabalho teve como objetivo estimar a prevalência de AIE em equídeos de tração no Distrito Federal, assim como identificar fatores de risco

\footnotetext{
${ }^{1}$ Recebido em 30 de setembro de 2015.

Aceito para publicação em 24 de fevereiro de 2017.

${ }^{2}$ Secretaria de Estado de Agricultura, Abastecimento e Desenvolvimento Rural (SEAGRI), SAIN Parque Rural, Edifício Sede, Brasília, DF 70620-000, Brasil.

${ }^{3}$ Hospital Veterinário de Grandes Animais, Faculdade de Agronomia e Medicina Veterinária, Universidade de Brasília (UnB), Galpão 3, Granja do Torto, Brasília, DF 70636-200, Brasil. *Autor para correspondência: jrborges@unb.br

${ }^{4}$ Laboratório de Epidemiologia Veterinária (EpiPLan), Faculdade de Agronomia e Medicina Veterinária, UnB, Campus Darcy Ribeiro, ICC Sul, ASS-128, Asa Norte, Brasília, DF 70919-970, Brasil.
}

associados à doença. Foram sorteados aleatoriamente 350 proprietários (Unidades Primárias de Amostragem- UPA) e foram amostrados todos os equídeos (Unidades secundárias de Amostragem) de cada proprietário sorteado, totalizando 496 animais. As amostras sanguíneas foram analisadas no Lanagro/MG por meio da técnica de imunodifusão em ágar gel (IDGA). No momento da coleta de sangue, também foi aplicado um questionário epidemiológico para a análise de possíveis fatores de risco. A prevalência de AIE nas UPA foi estimada em 2,29\%, (IC 95\%: 1,01-4,2\%) e nos animais foi de 1,81\% (IC 95\%: 0,55-3,07\%). A prevalência foi significativamente maior em muares do que em equinos. Não foi possível comprovar a presença de nenhum outro fator de risco associado à doença. Este estudo demonstra que a prevalência da AIE em equídeos de tração é baixa no Distrito Federal, porém mais alta do que os dados de vigilância de rotina sugerem, o que justifica a eutanásia dos equídeos reagentes, com a finalidade de promover a erradicação 
da enfermidade. Ratifica-se a importância da realização de exames periódicos nesses animais e a manutenção das atividades de vigilância.

TERMOS DE INDEXAÇÃO: Anemia infeciosa equina (AIE), equídeos de tração, prevalência, DF.

\section{INTRODUCĈ̃O}

A anemia infecciosa equina (AIE) é causada por um retrovírus da família Retroviridae, subfamília Lentivirinae (Gregg \& Polejaeva 2009, Cook et al. 2013). 0 vírus da AIE tem distribuição mundial especialmente em regiões de clima tropical e subtropical, onde existe grande quantidade de vetores (Koller et al. 2002). No Brasil, a doença é relatada desde 1968 nos estados do Rio Grande do Sul e Rio de Janeiro (Silva et al. 2001).

A transmissão da doença ocorre principalmente pela transferência de sangue e seus derivados de equídeos infectados para animais sadios, sendo que outras formas menos frequentes incluem as transmissões transplacentária, pelo colostro e sêmen (Nociti et al. 2008). McConnico et al. (2000) relataram que via colostro há a transmissão passiva de anticorpos contra AIE resultando em testes falso positivos nos potros filhos de éguas positivas. Devido a isso sugerem que após o desmame esses animais sejam mantidos em quarentena por pelo menos 45 dias antes de serem submetidos ao teste.

Os insetos hematófagos, com destaque para os tabanídeos, possuem papel importante na transmissão da doença como vetores mecânicos do vírus. Hawkins et al. (1973) demonstraram com facilidade a transmissão da doença por tabanídeo a partir de pôneis com infecção aguda, o que não foi observado a partir dos pôneis com infecção crônica e temperatura retal normal durante a exposição ao inseto. Barros \& Foil (2007) observaram o comportamento dos tabanídeos durante o repasto e reiteraram que a distância de 200 metros associada ao uso de barreiras físicas reduz a transmissão da AIE por meio desses vetores. Na transmissão iatrogênica o homem assume papel importante na epidemiologia da doença devido ao uso de agulhas, instrumentos cirúrgicos e utensílios contaminados, como freios e esporas (Coetzer et al. 1994), podendo disseminar a doença dentro de um mesmo rebanho ou até mesmo para outras propriedades devido às práticas inadequadas de higiene e manejo.

Grande parte dos animais são portadores assintomáticos da doença, porém, pode-se observar febre intermitente, trombocitopenia, anemia leve a moderada, anorexia, depressão, fraqueza, icterícia, edemas, petéquias nas mucosas e esplenomegalia. Equídeos que se recuperam da síndrome aguda podem desenvolver a síndrome subaguda ou crônica e os sinais clínicos são observados após situações estressantes ou após o uso de corticóides (Craigo et al. 2009).

Desde 1970, o teste de imunodifusão em gel de ágar (IDGA), também conhecido como teste de Coggins, é utilizado no diagnóstico da AIE, por ser de fácil execução (Issel \& Coggins 1979) e apresentar sensibilidade de $98,8 \%$ e especificidade de 100\% (Coggins et al. 1972). 0 ELISA também pode ser utilizado no diagnóstico da doença, porém o resul- tado positivo deve ser confirmado com o IDGA (OIE 2013). Em relação ao controle da doença, não há tratamento eficaz e deve basear-se na identificação e eutanásia dos positivos para saneamento do rebanho (Brasil 2004). No Pantanal, a AIE é considerada endêmica com alta prevalência e é aceita uma estratégia alternativa de controle da doença baseada no isolamento dos animais reagentes, visto que a eutanásia de todos os positivos seria inviável (Silva et al. 2001).

Segundo Almeida et al. (2006), os dados oficiais podem auxiliar a traçar um perfil epidemiológico da AIE, porém não informam com exatidão a taxa de prevalência da enfermidade nos diferentes estados do país, uma vez que se referem, exclusivamente, aos exames laboratoriais realizados para o trânsito interestadual e/ou participação em eventos agropecuários controlados pelos serviços oficiais de defesa sanitária animal. A maior parte do efetivo testado pertence a rebanhos de alto valor zootécnico em que a doença está controlada.

Alguns estudos realizados no Brasil revelam a situação da AIE em diferentes estados. Nociti et al. (2008) descreveram a ocorrência da AIE no estado do Mato Grosso, indicando frequência de animais positivos de 6,83\% em 2004, de $4,87 \%$ em 2005, de 4,71\% em 2006 e de 3,87\% em 2007. Melo et al. (2012) realizaram inquérito sorológico para as Encefalomielites Virais Equinas e para AIE nos três biomas do Mato Grosso e observaram prevalência de 5,1\% para AIE, sendo que no bioma pantanal foi observado o maior percentual de positivos e no bioma amazônico não foram observados positivos. Em um estudo realizado pela Embrapa Pantanal (Silva et al. 2001), foi observada prevalência de $18,2 \%$ em animais de serviço. Almeida et al. (2006) estimaram a prevalência da AIE em animais de serviço em 5,3\% em propriedades e $3,1 \%$ em animais, sendo a prevalência mais alta nas regiões Norte/Noroeste e Vale do Mucuri/Jequitinhonha, do que nas regiões ao centro e sul de MG. Fiorillo (2011) estimou a prevalência da AIE em haras de MG e verificou uma prevalência mais baixa quando comparada à dos animais de serviço. Na região Norte, Heinemann et al. (2002) relataram prevalência de $17,71 \%$ de AIE em animais de serviço no município de Uruará, estado do Pará, e afirmaram que a região amazônica é ecologicamente propícia ao desenvolvimento de insetos hematófagos, os quais constituem fator de grande importância para que a doença se mantenha de forma endêmica. Aguiar et al. (2008) estudaram a prevalência de anticorpos contra agentes virais e bacterianos em equídeos do município de Monte Negro, Rondônia, e constataram 9,6\% de animais reagentes para AIE.

No Distrito Federal, não havia sido realizado inquérito soroepidemiológico por amostragem aleatória para estimar a prevalência da AIE, somente existiam dados referentes a exames de rotina realizados em laboratórios credenciados. Os resultados dos testes de rotina para controle e vigilância de AIE (Quadro 1) demonstram que, entre 2007 e 2010, não houve grande variação da quantidade de equídeos testados para AIE em exames realizados nos laboratórios credenciados. Em 2010, 0,27\% dos equídeos testados foram positivos. A descrição epidemiológica da região por meio desses dados poderia trazer vieses importantes por duplicação de informação, já que um mesmo animal pode 
Quadro 1. Exames de AIE realizados no DF e número de animais positivos de 2004 a 2010

\begin{tabular}{ccccc}
\hline Ano & $\begin{array}{c}\text { Total de } \\
\text { Exames }\end{array}$ & Focos & $\begin{array}{c}\text { Animais } \\
\text { Positivos }\end{array}$ & $\begin{array}{c}\text { Animais } \\
\text { Positivos (\%) }\end{array}$ \\
\hline 2004 & 8.957 & 19 & 51 & 0,57 \\
2005 & 11.910 & 123 & 137 & 0,91 \\
2006 & 7.860 & 13 & 17 & 0,22 \\
2007 & 10.108 & 40 & 41 & 0,41 \\
2008 & 10.056 & 34 & 34 & 0,33 \\
2009 & 10.522 & 20 & 20 & 0,19 \\
2010 & 10.792 & 30 & 30 & 0,27
\end{tabular}

Quadro 2. Número de proprietários de equídeos de tração existentes por região e número de proprietários e animais amostrados por região

\begin{tabular}{cccccc}
\hline Região & $\begin{array}{c}\text { Total de } \\
\text { Proprietários }\end{array}$ & $\begin{array}{c}\text { Proprietários } \\
\text { Amostrados }\end{array}$ & $\begin{array}{c}\text { Animais } \\
\text { Amostrados }\end{array}$ & $\begin{array}{c}\text { Animais } \\
\text { Positivos }\end{array}$ \\
\hline 1 & Brazlândia & 549 & 181 & 264 & 4 \\
2 & Gama & 169 & 68 & 99 & 2 \\
3 & Sobradinho & 106 & 38 & 52 & 1 \\
4 & Planaltina & 189 & 63 & 81 & 2 \\
& TOTAL & 1013 & 350 & 496 & 9
\end{tabular}

realizar vários testes em um curto período de tempo, introduzindo um viés na estimativa de prevalência de AIE. Da mesma forma, é provável que a população testada não seja representativa da população de equídeos do DF. A maioria dos testes de AIE é realizada em animais de haras para finalidade de autorização de trânsito.

A população de equídeos de tração possui importância epidemiológica na disseminação da AIE no DF por não ser submetida a testes diagnósticos com periodicidade e por ser submetida à comercialização frequente, sendo muitos animais procedentes de regiões com grande quantidade de focos do estado de Goiás e norte de Minas Gerais. Além disso, esses animais transitam em área urbana e rural e muitos passam a noite em currais comunitários o que favorece a transmissão de diferentes patógenos.

Observando-se a importância econômica e social da equideocultura no Brasil e dos prejuízos causado pelas doenças que acometem os equídeos, principalmente, aquelas onde é obrigatória a eutanásia dos animais positivos, este trabalho teve como objetivo caracterizar a situação epidemiológica da anemia infecciosa equina em equídeos de tração do DF, estimando a prevalência desta doença e identificando possíveis fatores de risco associados a ela.

\section{MATERIAL E MÉTODOS}

Cálculo amostral. Para sorteio das unidades amostrais utilizou-se o banco de cadastro de proprietários de equídeos de tração do Distrito Federal organizado pela Secretaria de Agricultura e Desenvolvimento Rural do DF-SEAGRI-DF. Segundo o Decreto $\mathrm{n}^{0}$ 27.122, de agosto de 2006, compete a esta Secretaria realizar a identificação eletrônica e emitir a licença para os animais utilizados nos veículos de tração. Este banco de dados continha informações sobre 1013 proprietários e 1447 equídeos de tração (GDF 2006).

O número total de unidades primárias de amostragem - UPA (proprietários cadastrados que possuíam um ou mais animais de tração) foi determinado pela fórmula para amostras simples aleatórias, usando o programa Epi Tools ${ }^{\circledR}$. Os parâmetros adotados para o cálculo foram: nível de confiança de 0,95, prevalência estimada de 0,01 , erro de 0,01 e população total de 4100 equídeos. Considerando que a população de proprietários de equídeos de tração do DF é superior ao número cadastrado, utilizou-se para este cálculo uma população quatro vezes maior para evitar perda de precisão amostral. A capacidade operacional e financeira do serviço veterinário oficial também foi levada em consideração para a determinação do tamanho da amostra.

Assim, foi realizada uma amostragem aleatória simples sistemática de 350 UPA. 0 Banco de dados foi organizado de forma sequencial de acordo com as quatro regiões de escritórios da Diretoria de Defesa e Vigilância Sanitária da SEAGRI-DF que continham informações cadastradas. Dessa forma, o peso populacional das regiões do DF já foi considerado na amostra.

Cada unidade primária de amostragem teve todos os seus equídeos amostrados (Unidades Secundárias de AmostragemUSA). Conforme apresentado no quadro 2, foram amostrados 496 animais nas quatro regiões, representando cerca de 35\% da população cadastrada.

Em alguns casos não foi possível localizar os proprietários sorteados e estes proprietários foram substituídos por outros encontrados na mesma localidade.

Amostras. O sangue para os testes diagnóstico para AIE foi coletado por meio de punção da veia jugular, utilizando agulha individual e tubos de colheita a vácuo sem anticoagulante. Obteve-se uma amostra de $4 \mathrm{~mL}$ de sangue de cada animal. 0 soro foi separado por centrifugação, em centrífuga de ângulo fixo para tubos de $15 \mathrm{ml}$, durante 5 minutos a 2.500 rotações por minuto. As amostras foram fracionadas em dois microtubos plásticos de 1,5 $2 \mathrm{ml}$ por meio do uso de pipeta digital, identificadas e congeladas a $-20^{\circ} \mathrm{C}$. 0 processamento do sangue foi realizado no Laboratório de Anemia Infecciosa da SEAGRI/DF.

Diagnóstico. 0 soro congelado foi encaminhado em caixas de embalagem tripla, com gelo reciclável, por meio de transporte aéreo para o Laboratório Nacional Agropecuário do Ministério de Agricultura, Pecuária e Abastecimento, localizado em Pedro Leopoldo, Minas Gerais (Lanagro/MG. A segunda amostra permaneceu congelada no Laboratório da SEAGRI, caso fosse necessário envio de outra amostra para o laboratório oficial. 0 teste de imunodifusão em ágar gel (IDGA) foi o teste utilizado para o diagnóstico da doença, sendo esta técnica a única prescrita, oficialmente, para o trânsito de equídeos pela Organização Mundial de Saúde Animal.

Questionário. Junto a cada proprietário sorteado, além da coleta de sangue de seus animais para os testes diagnósticos, foi aplicado um questionário epidemiológico sobre informações específicas de cada animal e sobre atitudes e nível de conhecimento do proprietário sobre a doença para permitir a realização do estudo de possíveis fatores de risco associados à AIE. Todos os dados gerados nas coletas e testes laboratoriais foram inseridos em um banco de dados do Excel (Microsoft $囚$ ) e posteriormente analisados no programa estatístico STATA ${ }^{\circledR}$ (Stata Corp 2011), versão 11.0.

Análise estatística. Para a estimativa da prevalência de soropositividade para Anemia Infecciosa Equina nas UPA, utilizou-se a distribuição binomial exata para cálculo do erro padrão e consequente intervalo de confiança de 95\%. A UPA foi declarada positiva quando havia pelo menos um animal positivo. Para a prevalência nos animais, calculou-se a proporção de animais positivos usando os métodos apropriados para uma amostragem de conglomerados, neste caso realizada em uma única etapa.

A análise univariada de fatores de risco para AIE foi feita aplicando o teste do $\chi^{2}$. As variáveis obtidas por meio do questionário epidemiológico incluídas na análise foram: espécie, idade e sexo dos animais; número de equídeos do proprietário; local de 
aquisição dos animais; local onde os animais são abrigados e permanecem para repouso; utilização da mesma agulha para vários animais e periodicidade de realização de exames. Somente aquelas que possuíram um $\mathrm{p} \leq 0,05$ no teste foram consideradas estatisticamente significativas e associadas à presença de AIE. Não foi considerado o efeito do agrupamento (cluster) dos animais dado que a maioria dos proprietários possuía apenas um ou dois animais.

Não foi calculada a prevalência real, pois, neste caso, a prevalência aparente é uma ótima aproximação da real em virtude da alta sensibilidade e especificidade do teste de IDGA.

\section{RESULTADOS}

O Quadro 2 apresenta os dados demográficos da população alvo, assim como o número de proprietários (UPA) e de animais amostrados por região administrativa do DF, indicando também a distribuição regional de animais reagentes ao teste. A prevalência de AIE nas UPA foi de 2,29\%, com intervalo de confiança de $95 \%$ variando de $1,01 \%$ a $4,2 \%$. A prevalência de AIE em animais (USA) foi de 1,81\%, com intervalo de confiança de $95 \%$ variando de $0,55 \%$ a 3,07\%, portanto mais alta do que indicado pelos valores dos testes de rotina realizados nos DF.

Em relação à espécie, foram amostrados 478 equinos e 18 muares, sendo que foram reagentes ao teste 1,46\% (7) dos equinos e $11,11 \%$ (2) dos muares. Não foi observado nenhum asinino, pois esta espécie não é comumente utilizada como animal de tração no Distrito Federal. Ao realizar-se o teste do $\chi^{2}$, verificou-se haver associação entre os muares e a positividade para $\operatorname{AIE}(\mathrm{p}<0,005)$,

Em relação ao sexo, foram amostrados 302 machos e 194 fêmeas e não foi possível demonstrar associação entre positividade e sexo $(\mathrm{p}=0,72)$, conforme descrito no Quadro 3. Quanto à idade, observou-se que 69,96\% (347) dos animais possuíam entre 5 e 10 anos. Comparando-se as frequências de soropositividade para AIE entre equídeos jovens (até 4 anos), equídeos adultos (entre 5 e 10 anos) e equídeos idosos (acima de 10 anos), não foi possível afirmar que havia associação entre a idade e os casos positivos $(\mathrm{p}<0,5)$. Também não foi observada associação entre o local onde os equídeos permaneciam $(\mathrm{p}=0,98)$, ou onde os proprietários adquiriam seus animais $(p=0,26)$ e a soropositividade. Verificou-se que a maioria adquiria seus equídeos de outros proprietários e todos os animais positivos encontravam-se neste grupo.

No presente estudo foi observado que 79,14\% (277) dos proprietários tinha conhecimento sobre a AIE e 79,42\%

Quadro 3. Resultados da análise univariada pelo teste $\chi 2$ dos possíveis fatores de risco para AIE em equídeos de tração do Distrito Federal

\begin{tabular}{lc}
\hline Variável & $\mathrm{p}$ \\
\hline Espécie & 0,003 \\
Sexo & 0,72 \\
Idade & 0,4 \\
Local onde os equídeos permanecem & 0,98 \\
Onde adquirem os animais & 0,26 \\
Conhecimento sobre a AIE & 0,77 \\
Utiliza a mesma agulha nos animais & 0,75 \\
Frequência de realização de exames & 0,13
\end{tabular}

(278) responderam que não utilizavam a mesma agulha para aplicação de medicamentos em seus animais. Apesar do conhecimento sobre a doença, apenas 9,72\% (34) dos proprietários estavam com os exames de seus animais dentro do prazo de validade, outros $41,14 \%$ (144) nunca haviam submetido os equídeos ao exame de AIE e o restante $(49,14 \%$ - 172) estava com os exames fora do prazo de validade. Esses dados demonstram que os proprietários têm conhecimento sobre a doença e suas formas de transmissão, mas não reconhecem a importância da realização de testes periódicos dos animais. Isto se deve, principalmente, ao fato da não apresentação de sinais clínicos pelos equídeos soropositivos.

\section{DISCUSSÃO}

A AIE é endêmica no DF, porém a prevalência é baixa, sendo comparável à situação epidemiológica observada no sul de MG para animais de serviço (Almeida et al. 2006), mas mais baixa do que em regiões do Centro-Oeste e Norte do Brasil (Melo et al. 2012, Heinemann et al. 2002, Aguiar et al. 2008). No entanto, deve ser ressaltado que o presente estudo estimou a prevalência em animais em 1,81\%, bem acima do que indicam os testes de vigilância ativa no DF. Apesar da oferta desse serviço sem oneração, muitas vezes os proprietários são resistentes em permitir que o Serviço de Defesa realize a coleta de sangue de seus animais devido ao conhecimento da obrigatoriedade da eutanásia do animal positivo. Como a maior parte dos equídeos não apresenta qualquer sinal clínico da doença e são capazes de trabalhar nas carroças mesmo quando infectados, muitos proprietários preferem permanecer com os animais sem realizar os exames, a fim de evitar que seu animal seja recolhido. Assim, os resultados deste estudo fornecem subsídios mais próximos da realidade da subpopulação de equídeos de tração no DF e reforçam a necessidade do controle do trânsito desta subpopulação, visto que os proprietários têm o hábito de comprar animais não examinados provenientes do entorno do DF, onde é desconhecida a distribuição da AIE.

A baixa prevalência observada justifica a eutanásia dos equídeos após resultado positivo a fim de promover a erradicação dessa enfermidade, entretanto é necessário que se mantenha a realização de exames periódicos para que não haja acúmulo de casos e aumento da prevalência da doença. É importante ressaltar a necessidade da realização de exames periódicos pela Diretoria de Defesa Agropecuária da Secretaria de Agricultura, Abastecimento e Desenvolvimento Rural visto que os proprietários dos animais de tração não estão dispostos e, frequentemente, não têm condições financeiras para contratar um veterinário para realizar os exames dos equídeos. Tal como foi verificado em Minas Gerais (Almeida, 2006), se o controle da AIE em equídeos de tração não for eficaz, as ações relacionadas à população de animais de maior valor zootécnico ficam comprometidas, visto que as fontes de infecção são mantidas na região, aumentando o risco de sacrifício sanitário de equinos.

Agradecimentos.- Aos colegas de trabalho da SEAGRI-DF que contribuíram para a execução deste trabalho. 


\section{REFERÊNCIAS}

Aguiar D.M., Cavalcante G.T., Lara M.C.C.S.H., Villalobos E.M.C., Cunha E.M.C., Okuda L.H., Stéfano E., Nassar A.F.C., Souza G.O., Vasconcellos S.A., Labruna M.B., Camargo L.M.A. \& Gennari S.M. 2008. Prevalência de anticorpos contra agentes virais e bacterianos em equinos do município de Monte Negro, Rondônia, Amazônia Ocidental Brasileira. Braz. J. Vet. Res. Anim. Sci. 45(4):269-276.

Almeida V.M.A., Gonçalves V.S.P., Martins M.F., Haddad J.P.A., Dias R.A., Leite R.C. \& Reis J.K.P. 2006. Anemia infecciosa equina: prevalência em equídeos de serviço em Minas Gerais. Arq. Bras. Med. Vet. Zootec. 58(2): 141-148.

Barros A.T.M. \& Foil L.D. 2007. The influence of distance on movement of tabanids (Diptera: Tabanidae) between horses. Vet. Parasitol. 144:380-384.

Brasil 2004. Aprova as normas para a prevenção e o controle da Anemia Infecciosa Equina. Instrução Normativa ${ }^{\circ}$ 45, de 15 de junho de 2004. Disponível em <http://sistemasweb.agricultura.gov.br/sislegis/action/ detalhaAto.do?method=consultarLegislacaoFederal $>$ Acesso em 13 jun. 2016.

Coetzer J.A.W., Thomson G.R. \& Tustin R.C. 1994. Infectious diseases of livestock with special reference to Southern Africa. Vol.2. Oxford University Press, Cape Town, p.800-802.

Coggins L., Norcross N.L. \& Nusbaum S.R. 1972. Diagnosis of equine infectious anaemia by immunodifusion test. Am. J. Vet. Res. 33:11-18.

Cook R.F., Leroux C. \& Issel C.J. 2013. Equine infectious anemia and equine infectious anemia virus in 2013: a review. Vet. Microbiol. 167:181-204.

Craigo J.K., Barnes S., Zhang B., Cook S., Howe L., Issel C.J. \& Montelaro R.C. 2009. An EIAV field isolate reveals much higher levels of subtype variability than currently reported for the equine lentivirus family. Retrovirology 6(95)

Fiorillo K.S. 2011. Prevalência de anemia infecciosa equina em haras de Minas Gerais. Dissertação de Mestrado em Saúde Animal, Faculdade de Agronomia e Medicina Veterinária, Universidade de Brasília, Brasília, DF. 47p.

GDF 2006. Dispõe sobre o trânsito de veículos de tração animal nas vias públicas urbanas e faixas de domínio das rodovias no Distrito Federal. Governo do Distrito Federal. Decreto ${ }^{\circ}$ 27.122, de 28 de agosto de 2006. Disponível em <http://www.buriti.df.gov.br/ftp/diariooficial/2006/10_Outubro/DODF\%20205\%2025-10-2006/Seção01-\%20 205.pdf> Acesso em 19 mai. 2011.
Gregg K. \& Polejaeva I. 2009. Risk of equine infectious anemia virus disease transmission through in vitro embryo production using somatic cell nuclear tranfer. Theriogenology 72:289-299.

Hawkins J.A., Adams W.V., Cook L., Wilson B.H. \& Roth E.E. 1973. Role of horse fly (Tabanus fuscicoctatus Hine) and stable fly (Stomoxys calcitrans L.) in transmission of equine infectious anemia to ponies in Louisiana. Am. J. Vet. Res. 34(12):1583-1586.

Heinemann M.B., Cortez A., Souza M.C.C., Gotti T., Ferreira F., Homem V.S.F., Ferreira Neto J.S., Soares R.M., Sakamoto S.M., Cunha M.S. \& Richtzenhain L.J. 2002. Soroprevalência da anemia infecciosa equina, da arterite viral dos equinos e do aborto viral equino no município de Uruará, PA, Brasil. Braz. J. Vet. Res. Anim. Sci. 39(1):50-53.

Issel C.J. \& Coggins L. 1979. Equine infectious anemia: current knowledge. J. Am. Vet. Med. Assoc. 174(7):727-733.

Koller W.W., Barros A.T.M., Gomes A., Madruga C.R., Araújo C.P., Umaki A. \& Ismael A.P.K. 2002. Sazonalidade de tabanídeos (Diptera: Tabanidae) em área de transmissão entre cerrado e pantanal, no Mato Grosso do Sul, Brasil. $12^{\circ}$ Congresso Brasileiro de Parasitologia Veterinária, Rio de Janeiro, Programas e Resumos, Rio de Janeiro.

McConnico R.S., Issel C.J., Cook S.J., Cook R.F., Floyd C. \& Bisson H. 2000. Predictive methods to define infection with equine infectious anemia virus in foals out of reactor mares. J. Equine Vet. Sci. 20(6):387-392.

Melo R.M., Cavalcanti R.C., Villalobos E.M.S., Cunha E.M.S., Lara M.C.C.S.H. \& Aguiar D.M. 2012. Ocorrência de equídeos soropositivos para os vírus das encefalomielites e anemia infecciosa no estado de Mato Grosso. Arqs Inst. Biológico, São Paulo, 79(2):169-175.

Nociti R.P., Nociti D.L.P., Rocha T.G., Avila M.O. \& Silva G.C.P. 2008. Prevalência da anemia infecciosa equina no estado do Mato Grosso de 2004 a 2007. Disponível em <http://www.sovergs.com.br/conbravet2008/ anais/cd/resumos/R0630-3.pdf> Acesso em 24 nov. 2010.

OIE 2013. Terrestrial Manual, World Organization for Animal Health. Cap. 2.5.6. Disponível em <http://www.oie.int/fileadmin/Home/eng/Health_standards/tahm/2.05.06_EIA.pdf> Acesso em 20 jun. 2016.

Silva R.A.M.S., Abreu U.G.P. \& Barros A.T.M. 2001. Anemia Infecciosa Equina: Epizootiologia, Prevenção e Controle no Pantanal. Circ. Téc. no. 29, Embrapa Pantanal, Corumbá, MS. 32p.

Stata Corp. 2011. Stata: Release 12. Statistical Software. College Station, TX: StataCorp LP. 